\title{
Prices as Factors: Approximate Aggregation with Incomplete Markets*
}

\author{
Chris I. Telmer ${ }^{\dagger} \quad$ Stanley E. Zin ${ }^{\ddagger}$
}

December 1999, revised August 2000

\begin{abstract}
Recent developments in intertemporal asset pricing theory focus on two sets of fundamental determinants of asset returns. Models with complete markets emphasize aggregate variables such as per capita consumption. Such models have not performed well empirically. Models with incomplete markets models emphasize disaggregate variables such as the distribution of wealth. These models have shown empirical promise, but their lack of parsimony has led many to question their usefulness. Indeed, most empirical applications, as well as the best practice in the financial industry, ignore much of what theory has to say altogether. Practitioners favor factor models and, in particular, models in which asset returns serve as factors that explain other asset returns. This paper attempts to rationalize these very different approaches. We show that in an incomplete-markets economy - an economy in which the true pricing kernel is high dimensional and difficult to measure - a low-dimensional pricing kernel that depends on returns, as in the CAPM or the APT, can accurately price assets. In this sense, theory based on fundamentals admits an approximate aggregation that is consistent with practical application. Theory and practice, therefore, may not be as disparate as they might seem. In fact, we argue that general equilibrium models with frictions can be useful in providing guidance for the specification of better empirical models.
\end{abstract}

\footnotetext{
*This paper previously circulated as "Approximate Aggregation with Incomplete Markets," first draft, December 1993. In addition to numberous participants at seminars and conferences, we thank Dave Backus, Phil Dybvig, Larry Epstein, Ed Green, Rick Green, Allan Gregory, Burton Hollifield, Tom Sargent, Fallaw Sowell and Amir Yaron for helpful comments and suggestions.

†GSIA, Carnegie Mellon University, chris.telmer@cmu.edu

${ }^{\ddagger}$ GSIA, Carnegie Mellon University and NBER, zin@bobbyorr.gsia.cmu.edu
} 


\section{Introduction}

A central goal of financial economics is to find a parsimonious representation of a pricing kernel, a positive random variable, $M_{t}$, that satisfies the no-arbitrage condition: $E_{t}\left(M_{t+1} R_{t+1}\right)=1$, where $R_{t+1}$ represents a vector of asset returns. Knowledge of the form of such a random variable is sufficient for the valuation of any statecontingent cash flow. A popular approach has been to put sufficient structure on a model economy so that $M_{t}$ is a simple function of aggregate consumption, independent of the distribution of wealth. Lucas (1978), for example, studies a model in which $M_{t}$ is coincident with the intertemporal marginal rate of substitution of a single, or representative, agent who consumes aggregate consumption in equilibrium. Constantinides (1982) shows that this representative-agent pricing kernel can result from a complete-markets equilibrium in which many different agents seek to maximize additively time-separable expected utility. Breeden (1979) and Grossman and Shiller (1982) show that in a continuous-time economy, or a discrete economy in which utility is quadratic, several other forms of heterogeneity are consistent with an aggregate consumption-based pricing kernel.

The quantitative shortcomings of specific parameterizations of the aggregate consumption version of $M_{t}$ has led a number of authors (e.g., Aiyagari and Gertler (1991), Alvarez and Jermann (1997), Constantinides and Duffie (1996), den Haan (1994), Heaton and Lucas (1996), Levine and Zame (2000), Lucas (1994), Mankiw (1986), Marcet and Singleton (1991), Telmer (1993) Krusell and Smith (1997), and Zhang (1997)) to consider environments in which aggregation (in the sense of Constantinides (1982)) doesn't hold. In these environments frictions in the intertemporal trading mechanism - an insufficient number of state contingent claims, for instance - force agents to bear a portion of their idiosyncratic risk in equilibrium, thereby increasing the variability of $M_{t}$. Hansen and Jagannathan (1991) have shown that achieving a certain amount of variability in the pricing kernel is a necessary condition for understanding the behavior of excess returns on risky assets.

These asset-pricing theories have a number of potential benefits, the most obvious being that they provide formal models of the relationship between prices and quantities, thereby linking what we mean by risk to fundamentals such as preferences and technologies. Just as obvious, however, are the drawbacks associated with this approach. In many instances valuation can be high dimensional: a large number of state variables, the distribution of wealth for instance, are necessary for a characterization of equilibrium prices. This lack of parsimony stands in sharp contrast to a number of alternative valuation models that attain low dimensionality by assuming frictionless environments. Classic examples are the CAPM of Sharpe (1964) and Lintner (1965) and Ross's (1976) APT. More recent examples are factor-based approaches such as (among many others) Bossaerts and Green (1989), Chen, Roll, and Ross (1986), Fama and French (1996), Ferson and Harvey (1991)), Jagannathan

and Wang (1996) and Lehmann and Modest (1988). One unifying theme of these 
models is that the underlying pricing kernel is usually a low-dimensional function of prices, not quantities such as consumption. Another feature of these models is that, not surprisingly given their empirical motivation, they "work better." In almost any applied situation a practitioner is far more likely to use a return-based pricing kernel than a consumption-based alternative.

The main goal of this paper is to provide a link between the fully specified equilibrium approach and the factor-based (or "price-driven") approach that is commonly used in practical applications. Our hope is that the characterization of this link will provide useful theoretical guidance for the selection of factor structures, as well as providing some general support for fundamentals-based research. We consider a simple incomplete markets model in which idiosyncratic endowment risk cannot be directly insured against. Pricing is necessarily high dimensional in this environment: the (non-unique) pricing kernel depends on the cross-sectional distribution of asset holdings. The central question we ask is "how well does a suitably parameterized function of aggregate information (e.g., asset returns) approximate the true pricing kernel in our theoretical economy?" This is the sense in which our question is related to "approximate aggregation."

It is worth noting that, for the class of incomplete markets models we study here, several polar cases have already been identified in which approximate aggregation obtains. Constantinides and Duffie (1996) provide an example in which the idiosyncratic component of individual income is non-stationary, equilibrium is autarkic and an aggregate consumption-based representation of the pricing kernel obtains. The pricing kernel has a representative-agent interpretation, however the representative agent's preferences depend on both individual preferences and income processes. In this sense Constantinides and Duffie's aggregation results are perhaps most accurately described as "mongrel aggregation." At the other extreme, the results of Heaton and Lucas (1996), Krusell and Smith (1997), Lucas (1994), Telmer (1993) and others, suggest that, under certain conditions, transitory idiosyncratic shocks can be almost perfectly pooled by trading in a limited set of financial markets. In these models the equilibrium pricing kernel can be well approximated with the aggregate consumption-based solution from the representative-agent model.

Our main findings relate to environments between these two extremes, where trade flows are non-degenerate but — due to stringent borrowing constraints allocations and prices are substantially different from their complete-markets counterparts. We find that, in these environments, structural asset-pricing models with a strong theoretical base need not be at odds with reduced-form specifications which, in practice, tend to "work better." In particular, pricing kernels that are simple functions of equilibrium prices (or returns), provide good proxies for the true pricing kernels which are typically higher-dimensional functions of disaggregate information. The reason is straightforward. In our model, equilibrium returns vary across the distribution the wealth. Our results simply suggest that a suitably parameterized 
function of these returns is able to reveal much of the relevant information regarding the underlying variation in the wealth distribution.

A specific outline of the paper is as follows. In Section 2 we present a general formulation of an incomplete markets economy. A precise statement of what is meant by the term "approximate aggregation" is provided. Section 3 briefly reviews the Constantinides and Duffie (1996) conditions which give rise to an autarkic equilibrium and then goes on to develop several extensions that incorporate habit formation, state nonseparable utility and a regime switching process. Each example illustrates a particular case of "mongrel aggregation," where aggregate pricing relationships hold exactly but where the preference parameters of the representative agent do not necessarily coincide with those of actual agents. Our extensions of the basic Constantinides and Duffie (1996) specification, in particular, show how incomplete markets can give rise to aggregate preferences that have a completely different structure than individual preferences. Section 3 concludes by considering an economy with a non-degenerate volume of trade and sets the stage for our analysis of approximate aggregation. In Section 4 we consider three different classes of approximate pricing kernels. The first two are based on preference specifications which have been popular in a representative agent context, the idea being to ask if mongrel aggregation results similar to Constantinides and Duffie's hold (approximately) in an economy with trade. The third is based on a simple linear-factor specification. In each case we examine the magnitude of the associated approximation error using several different evaluation criteria. Section 6 offers concluding remarks.

\section{General Formulation}

We study a popular class of heterogeneous-agent exchange economies in which heterogeneity arises from the inability to pool idiosyncratic endowment risks due to incomplete financial markets for state-contingent claims. A fundamental feature of these economies is the information structure. The increasing set of $\sigma$-algebras (information sets), $F \equiv\left\{\mathcal{F}_{t}: \mathcal{F}_{t} \subseteq \mathcal{F}_{t+1}\right\}$, will be used to denote information that is observable at time $t$ at both both the aggregate and the individual level. The set $G \equiv\left\{\mathcal{G}_{t}: \mathcal{G}_{t} \subseteq \mathcal{G}_{t+1}\right\}$, will denote information that is observable only at the aggregate level. By construction then, $\mathcal{G}_{t} \subseteq \mathcal{F}_{t}$. Note that individual specific random variables, labor income and portfolio composition in particular, will be $\mathcal{F}_{t}$ -measurable, but not $\mathcal{G}_{t}$-measurable.

Equilibrium will be partially described by an $\mathcal{F}_{t}$-measurable linear pricing functional mapping state-contingent payoffs into state-contingent prices. Consequently, our formulation will admit (see Duffie (1996)) the existence of a class of random variables, $M_{t}$, which satisfy

$$
E\left(M_{t+1} R_{t+1} \mid \mathcal{F}_{t}\right)=1
$$


where $R_{t+1}$ is a vector of asset returns. We refer to the random variable $M_{t+1}$ as the pricing kernel or, when weighted by appropriate probabilities, as the state-price density. Our goal is to ask to what extent the $\mathcal{F}_{t}$-measurable pricing kernel can be represented as a $\mathcal{G}_{t}$-measurable random variable, $M_{t}^{G}$. Exact aggregation implies that $E\left(M_{t+1}^{G} R_{t+1} \mid \mathcal{F}_{t}\right)=1$. In general, the model does not allow exact aggregation, so we will be interested in approximate aggregation. The essence of our question involves assessing the economic relevance of the projection $E\left(\left[M_{t+1}-M_{t+1}^{G}\right] R_{t+1} \mid \mathcal{F}_{t}\right)$. For notational convenience, we define the operator $E_{t}(x) \equiv E\left(x \mid \mathcal{F}_{t}\right)$. When the conditioning set is required to be $\mathcal{G}_{t}$ we will denote this explicitly.

We begin by specifying an economic environment. There are $m$ infinitely-lived consumers who seek to maximize identical, additively time-separable expected utility functions of the form

$$
U_{i 0}=E_{0}\left[\sum_{t=0}^{\infty}\left(\frac{1}{1+\delta}\right)^{t} u\left(C_{i t}\right)\right]
$$

where $C_{i t}$ denotes consumption of the single, perishable good by individual $i$ at time $t$, and $\delta$ is the rate of time preference. All agents have identical information.

Each individual derives income, $Y_{i t}$, from two sources: exogenously determined labor income and payoffs from holding financial securities. The stochastic process for labor income has both a systematic component, $I_{t}$, and an idiosyncratic component, $Z_{i t}$. That is, $Y_{i t}=Y\left(I_{t}, Z_{i t}\right)$, such that $\sum_{i=1}^{m} Y_{i t}=I_{t}$. In terms of the information structure, $I_{t}$ is $\mathcal{G}_{t}$-measurable (and therefore $\mathcal{F}_{t}$-measurable) but $Z_{i t}$ is not.

Financial markets are plentiful in this environment. There are $n$ securities (each with a fixed supply of 1 ), paying dividends $d_{j t}$ with prices $P_{j t}$. In addition, there are discount bonds (in zero net supply) of all maturities $<\tau^{*}$ with face values of 1 and with prices $B_{t, \tau}$. Each agent has a capital endowment of $1 / m$ shares of each security. Aggregate income (and therefore aggregate consumption) is given by $Y_{t} \equiv m I_{t}+D_{t}$, where $D_{t}=\sum_{j=1}^{n} d_{j t}$, is the aggregate dividend. All payoffs and prices are assumed to be elements of the aggregate information set, $G$.

A crucial assumption is that agents are prohibited from trading in claims with payoffs which are not $\mathcal{G}_{t}$-measurable. This restriction applies to both insurancetype claims written directly on outcomes of $Z_{i t}$, as well as to financial assets. The result is that financial markets are dynamically incomplete. Without this restriction this environment permits exact consumer aggregation in the sense of Constantinides (1982).

Each consumer, $i$, will choose a consumption sequence, $\left\{C_{i t}\right\}_{t=0}^{\infty}$, supported by an admissible trading strategy, $\left\{\theta_{j t}^{i}, b_{t, t+\tau}^{i}\right\}_{t=0}^{\infty}, j=1,2, \ldots, n, \tau=1,2, \ldots, \tau^{*}$ (where $\theta_{j t}^{i}$ is agent- $i$ 's holdings of asset- $j$ at date $t$, and $b_{t, t+\tau}^{i}$ are agent- $i$ 's holdings of the discount bond of maturity $\tau$ ), to maximize utility subject to the budget constraint 


$$
\begin{aligned}
C_{i t} & =Y_{i t}+\sum_{j=1}^{n} \theta_{j, t-1}^{i}\left(P_{j t}+d_{j t}\right)+\sum_{\tau=0}^{\tau^{*}-1} b_{t-1, t+\tau}^{i} B_{t, t+\tau} \\
& -\sum_{j=1}^{n} \theta_{j, t}^{i} P_{j, t}-\sum_{\tau=1}^{\tau^{*}} b_{t, t+\tau}^{i} B_{t, t+\tau}
\end{aligned}
$$

with initial conditions

$$
\theta_{j,-1}^{i}=1 / m
$$

and

$$
b_{-1, \tau}^{i}=0
$$

In a competitive equilibrium, the agents maximize utility, markets clear (i.e., for all $t, \sum_{i=1}^{m} b_{t, t+\tau}^{i}=0, \tau=1,2, \ldots, \tau^{*}$, and $\left.\sum_{i=1}^{m} \theta_{j t}^{i}=1, j=1,2, \ldots, n\right)$, and price expectations are fulfilled.

\section{$3 \quad$ Theoretical Examples}

\subsection{Autarkic Economies}

Constantinides and Duffie (1996) consider a version of this economy in which preferences are of the time-additive constant-absolute-risk-aversion form and the stochastic process for labor income has additive idiosyncratic shocks:

$$
\begin{gathered}
U_{i 0}=E_{0}\left[-\alpha^{-1} \sum_{t=0}^{\infty} \exp \left(-\delta t-\alpha C_{i t}\right)\right], \\
Y_{i t}=I_{t}+Z_{i t} .
\end{gathered}
$$

Further, assume that the dynamics of the idiosyncratic component of income evolves according to the process:

$$
(1-L) Z_{i t}=2 \sigma \epsilon_{i t}+\left[2 \beta+2 \gamma(1-L)\left(I_{t}+\frac{D_{t}}{m}\right)\right]^{1 / 2} \eta_{i t}
$$

where

$$
\epsilon_{i t}, \eta_{i t} \sim \text { i.i.d.N }(0,1)
$$




$$
\sum_{i=1}^{m} \epsilon_{i t}=\sum_{i=1}^{m} \eta_{i t}=0
$$

and $L$ is the lag operator. Note that the process for $Z_{i t}$ has a unit root. This assumption plays a critical role in the determination of the equilibrium volume of trade in financial securities. In addition, note that although $(1-L) Z_{i t}$ is uncorrelated across households, it is not independent. The conditional variance, but not the conditional mean, of $(1-L) Z_{i t}$ is dependent on the first difference of the aggregate shock. We will return to the significance of these properties shortly.

Constantinides and Duffie show that in this economy, the competitive equilibrium is autarky. That is, equilibrium allocations and prices satisfy:

$$
\begin{gathered}
\theta_{i t}=1 / m, \quad b_{i t}=0, \\
C_{i t}=\frac{D_{t}}{m}+I_{t}+Z_{i t}, \\
P_{j t}=E_{t}\left[\sum_{\tau=1}^{\infty} M_{t+\tau, t}^{*} d_{j, t+\tau}\right],
\end{gathered}
$$

and

$$
B_{t, \tau}=E_{t}\left[M_{t+\tau, t}^{*}\right],
$$

where the pricing kernel is given by

$$
M_{t+\tau, t}^{*}=\exp \left[-\tau \delta^{*}-\alpha^{*}(1-L)^{\tau}\left(\frac{D_{t+\tau}}{m}+I_{t+\tau}\right)\right]
$$

and

$$
\delta^{*}=\delta-\alpha^{2} \sigma^{2}-\alpha^{2} \beta, \alpha^{*}=\alpha-\alpha^{2} \gamma
$$

It is important to note that this is the same equilibrium, and the same pricing kernel, that would obtain in a representative agent model with endowments $\frac{D_{t}}{m}+I_{t}$ and preference parameters $\delta^{*}, \alpha^{*}$. This lies at the heart of Constantinides and Duffie's (1996) insight. The extremely large risk aversion and negative discounting necessary to generate a large average equity premium with a low riskless interest rate in a representative-agent model - the equity premium puzzle of Mehra and Prescott (1985) - may say very little about individual preferences, since the parameters that affect asset prices are combinations of preference and technology (e.g., income), parameters.

This result is substantially different from other models with heterogeneity which invariably generate trade and risk sharing across agents. The intuition behind this difference is relatively straightforward. Direct cross-sectional risk sharing of the idiosyncratic component of income is ruled out by the market structure. That is, 
contingent claims markets for these events do not exist. Further, the unit root in the endowment process combined with the assumption of time-additive preferences rules out intertemporal consumption smoothing. For example, if an agent receives a large positive shock to income, and if income is a stationary process, then the agent would expect a comparable drop in income at some future date, hence, would want to balance today's low marginal utility with that future period's high marginal utility by buying a bond (or some other comparable investment strategy). In this model, the agent has the expectation that the income shock is permanent, hence, the shock will never be offset at some future date. There is therefore no ex ante desire to smooth consumption intertemporally, and hence no desire to deviate from autarky.

\subsection{Time Nonseparable Utility}

Consider the same basic model as Constantides and Duffie but now allow for nonseparabilities in intertemporal utility. In other words, maintain the same economic assumptions as in Section 3.1, but assume that each agent's preferences are given by:

$$
E_{0}\left[-\lambda^{-1} \sum_{t=0}^{\infty} \exp \left(-\rho t-C_{i t}^{*}\right)\right],
$$

where the consumption service flow process, $C_{i t}^{*}$, is given by

$$
C_{i t}^{*}=C_{i t}+\alpha C_{i, t-1}
$$

(Extensions to service flow processes with higher-order lags is straightforward.)

Assume that the idiosyncratic income process is given by

$$
A(L) Z_{i t}=\eta_{i t}
$$

where

$$
\sum_{i=1}^{m} \eta_{i t}=0
$$

and

$$
\eta_{i t} \mid Y_{t}, Y_{t-1} \sim N\left(0,2 \gamma_{0}+2 \gamma_{1}\left(Y_{t}+\alpha Y_{t-1}\right)\right) .
$$

The basic result for this model is that if

$$
A(L)=(1-L)(1+\alpha L)
$$

then the competitive equilibrium is, once again consistent with autarky. That is, the equilibrium is given by:

$$
\theta_{i t}=1 / m, \quad b_{i t}=0, C_{i t}=\frac{D_{t}}{m}+I_{t}+Z_{i t},
$$




$$
P_{j t}=E_{t}\left[\sum_{\tau=1}^{\infty} M R S_{t+\tau, t}^{*} d_{j, t+\tau}\right]
$$

and

$$
B_{t, \tau}=E_{t}\left[M R S_{t+\tau, t}^{*}\right],
$$

where

$$
\begin{gathered}
M R S_{t+\tau, t}^{*}=M R S_{t+1, t}^{*} M R S_{t+2, t+1}^{*} \cdots M R S_{t+\tau, t+\tau-1}^{*} \\
M R S_{t+1, t}^{*}=\frac{\beta^{*}\left[\exp \left(-\lambda^{*} Y_{t+1}^{*}\right)+\alpha \beta^{*} \exp \left(-\lambda^{*} Y_{t+2}^{*}\right)\right]}{E_{t}\left[\exp \left(-\lambda^{*} Y_{t}^{*}\right)+\alpha \beta^{*} \exp \left(-\lambda^{*} Y_{t+1}^{*}\right)\right]} \\
Y_{t}^{*}=(1+\alpha L)\left[\frac{D_{t}}{m}+I_{t}\right]
\end{gathered}
$$

and

$$
\beta^{*}=\exp \left(-\rho+\lambda^{2} \gamma_{0}\right), \quad \lambda^{*}=\lambda-\lambda^{2} \gamma_{1}
$$

The no trade intuition for this model is exactly the same as before. The idiosyncratic shock to consumption services flows created by the income shock has a permanent effect on expected marginal utility, hence, is will not be shared across agents. In addition, a single-agent representation still holds for this economy. The "preference" parameters for the representative agent differ from individuals' preferences as they did in the previous example with the exception of $\alpha$. This habits/durability parameter is the same for the representative agent as it is for the individual agents. It is worth noting that the relationship between preferences and the idiosyncratic income shock seems more elaborate than in the time-additive case but, in fact, it is "rigged" in exactly the same fashion to guarantee the absence of trade. By using the same parameter $\alpha$ in preferences and in the income process we have guaranteed that process for the endowment of consumption service flows has a unit root as it did in the model without habits or durability.

The sensitivity of these aggregation results to the specific parameterizations is somewhat subtle. For example, if the conditional variance of the idiosyncratic income shock does not depend on the preference parameter $\alpha$ we will get aggregation but with a different type of representative consumer. For example, consider a slightly different process for the innovations to idiosyncratic income. That is, replace the assumption

$$
\eta_{i t} \mid Y_{t}, Y_{t-1} \sim N\left(0,2 \gamma_{0}+2 \gamma_{1}\left(Y_{t}+\alpha Y_{t-1}\right)\right)
$$

with the assumption

$$
\eta_{i t} \mid Y_{t}, Y_{t-1} \sim N\left(0,2 \gamma_{0}+2 \gamma_{1}(1-L) Y_{t}\right) .
$$

(Note the new assumption removes $\alpha$ from the conditional variance.) 
In this case, autarky is still the competitive equilibrium since service flow endowments still have a unit root, but now the representative agent has preferences that are in a slightly different class with different parameters. That is,

$$
M R S_{t+1, t}^{*}=\frac{\beta^{*}\left[\exp \left(-\lambda^{*} Y_{t+1}^{* *}\right)+\alpha \beta^{*} \exp \left(-\lambda^{*} Y_{t+2}^{* *}\right)\right]}{E_{t}\left[\exp \left(-\lambda^{*} Y_{t}^{* *}\right)+\alpha \beta^{*} \exp \left(-\lambda^{*} Y_{t+1}^{* *}\right)\right]},
$$

where

$$
\begin{gathered}
Y_{t}^{* *}=Y_{t}+\alpha^{*} Y_{t-1} \\
\beta^{*}=\exp \left(-\rho+\lambda^{2} \gamma_{0}\right), \quad \lambda^{*}=\lambda-\lambda^{2} \gamma_{1}, \quad \alpha^{*}=\frac{\alpha \lambda}{\lambda^{*}} .
\end{gathered}
$$

Note that there is now a potential for misspecification of preferences at the aggregate level. Habits at the individual-consumer level can look like durability in the representative-agent level, and vice versa, depending on the specific parameter values chosen.

The conclusion, therefore, is that representative-agent habits/durable-goods models are compatible with the general framework with heterogeneity. However, the persistence parameters in preferences and the persistence parameters governing the process for idiosyncratic income must be closely related (as, in fact, they implicitly are in the time-additive model).

\subsection{State Nonseparable Utility and Stochastic Switching}

We now turn to an example where aggregation holds but the representative agent's preferences look nothing like those of an individual agent. In the examples discussed so far, the conditional mean and variance of the innovation to the idiosyncratic income process have been continuous functions of the aggregate state variables. We now demonstrate the implications of a discontinuity in one of these functions. That is, define the idiosyncratic income process as follows:

$$
(1-L) Z_{i t}=\eta_{i t}
$$

where

$$
\operatorname{Var}\left[\eta_{i t} \mid Y_{t}, Y_{t-1}\right]= \begin{cases}1 & \text { if }(1-L) Y_{t}<g \\ A & \text { if }(1-L) Y_{t}>g\end{cases}
$$

In this case, autarky is once again the competitive equilibrium for the same reasons detailed in the other examples. The representative agent's preferences, however, have a completely different structure from individual preferences. The marginal rate of intertemporal substitution is given by:

$$
M_{t, t-1}^{*}=\left\{\exp \left[-\rho-\lambda(1-L) Y_{t}\right]\right\} I_{A}\left[(1-L) Y_{t}\right]
$$


where $I_{A}[\cdot]$ is the indicator function assigning the value 1 when $(1-L) Y_{t}<g$ and $A$ otherwise.

Figures 1 to 3 demonstrate the time-series properties of this marginal rate of substitution process. Aggregate per capita monthly consumption of nondurables is used as a measure of the aggregate endowment process. The data are from the beginning of 1959 to the end of 1990. The parameters are set such that $\lambda=2$ and $g$ is the sample average of the change in consumption. The parameter $A$ varies to 1 (Figure 1) to 0.8 (Figure 2) to 0.6 (Figure 3). The interpretation of this parameter is that when the change in the aggregate endowment is above its mean, the distribution of the innovation in idiosyncratic income has a variance that is $100 \mathrm{~A} \%$ as large as in states when the change in the aggregate endowment is below its mean. The top panel provides a time-series plot of the ex post log marginal rate of substitution. The bottom panel displays the unconditional histogram for this process. Visual examination of these figures lead to the conclusion that the $M$ process looks like a stochastic switching model for the aggregate endowment that switches from a distribution with a high mean to one with a low mean, in a negatively autocorrelated fashion. This process bears a striking resemblance to the Disappointment Aversion model studied in Epstein and Zin (1991a), which in turn bears a close resemblance to the models of Cecchetti, Lam, and Mark (1993) in which the aggregate endowment is a switching process. It differs conceptually from the former class of models in that individual preferences have a simple expected utility form and it differs from the latter class in that aggregate consumption/income in the model does not exhibit stochastic switching. The aggregate behavior in this case is generated strictly from the properties of idiosyncratic income (particularly its time threshold-like stochastic volatility), and the inability of agents to hedge these idiosyncratic shocks.

\subsection{Economies with Trade}

The Constantinides and Duffie model demonstrates that if preferences and the stochastic process describing labor income are judiciously parameterized, the pricing kernel depends only on aggregate information. The parameter values for the aggregate information-based pricing kernel in these economies, however, cannot be literally interpreted as representing the preferences of some actual agent. We now investigate the extent to which similar aggregation results obtain in economies with a non-degenerate volume of trade in financial assets. To do this we relax the assumption that the idiosyncratic component of individual income takes on the specialized, non-stationary, form outlined above. Analytical solutions are not generally available for these types of dynamic, stochastic heterogeneous agent environments. We rely on a simplified structure, both in terms of financial markets and the agent population, as well as numerical solution methods in order to perform our analysis.

Consider the following restrictions on the general framework of Section 2. There 
are two consumers $(m=2)$ with preferences given by,

$$
E_{0}\left[\sum_{t=0}^{\infty}\left(\frac{1}{1+\delta}\right)^{t} \frac{C_{i t}^{1-\alpha}}{(1-\alpha)}\right]
$$

where $\alpha$ is the relative risk aversion parameter and $\delta$ is the rate of time preference. Individual income processes are given by

$$
Y_{i t}=I_{t} Z_{i t}
$$

where the idiosyncratic part of income, $Z_{i t}$, takes the form of a stochastic sharing rule. Since this sharing rule must satisfy $Z_{1 t}+Z_{2 t}=1$, we can ignore $Z_{2 t}$. Note that, although the notation hasn't changed, the meaning of the idiosyncratic shock here is different than in the Constantinides and Duffie specification. Here the shock is to the share of aggregate income accruing to the individual, whereas in their specification idiosyncratic income was an additive shock to aggregate income, necessitated by the use of exponential preferences.

We begin by abstracting from the state-dependent conditional variances that played such an important role in the previous models, and formulate the aggregate and idiosyncratic processes simply as first order autoregressions:

$$
\begin{aligned}
(1-\rho L)(1-L) \log I_{t} & =\mu+\varepsilon_{t} \\
\left(1-\rho_{z} L\right) \log Z_{1 t} & =\mu_{z}+\varepsilon_{z t} .
\end{aligned}
$$

When solving the model, we approximate these first-order autoregressions with finite-state Markov chains. The reason that we initially specify these processes as continuous-state autoregressions is to clarify the issue of how persistence will be represented in our analysis. When considering economies with an increased degree of persistence in the $Z_{1 t}$ process we will hold the conditional variance function constant, as is the case when one increases the value of the $\rho_{z}$ in the autoregressive model while holding the innovation variance fixed. Note that this approach contrasts the common method of representing persistence in a Markov chain: parameterizing the transition matrix with large diagonal elements. In the latter case, the unconditional variance is being held constant, while the conditional variance function is being driven to zero.

There are two securities in this economy, one traded and one non-traded. The traded security is a single-period discount bond in zero net supply, with price $B_{t}$ and face value of one unit of consumption. Trading in this security is limited by a borrowing constraint, $b_{i t} \geq \bar{b}, \bar{b}<0$. In states in which the borrowing constraint is 
binding, the equilibrium bond price will be determined by the unconstrained agent, i.e., the constraint applies to the short side of the market, not the long side. The non-traded security is a claim on the value of the aggregate endowment with a price, $P_{t}$, that is determined as $\max \left(P_{1 t}, P_{2 t}\right)$, where $P_{i t}, i=1,2$ is agent $i$ 's shadow price for the aggregate endowment.

A competitive equilibrium for this economy is described by initial conditions, $b_{i t}$, and the following system of equations:

$$
\begin{aligned}
B_{t} & \geq E_{t}\left[m_{t+1, t}^{i}, i=1,2\right. \\
P_{t} & \geq E_{t}\left[\sum_{\tau=1}^{\infty} m_{t+\tau, t}^{i} 2 I_{t+\tau}\right], i=1,2 \\
C_{i t} & =Y_{i t}+b_{i, t-1}-B_{t} b_{i t}, \quad i=1,2 \\
0 & =b_{1 t}+b_{2 t} \\
b_{i t} & \geq \bar{b} \\
\theta_{i t} & =0
\end{aligned}
$$

where

$$
m_{t+1, t}^{i}=\left(\frac{1}{1+\delta}\right)\left(\frac{C_{i, t+1}}{C_{i, t}}\right)^{-\alpha}
$$

Note that, due to the presence of potentially binding borrowing constraints, the individual specific marginal rates of substitution will not satisfy the definition of a pricing kernel. Define the indicator variables $\mathbf{1}\left(b_{i t}>\bar{b}\right)$, for $i=1,2$ as

$$
\mathbf{1}\left(b_{i t}>\bar{b}\right)= \begin{cases}1 & \text { if } b_{i t}>\bar{b} \\ 0 & \text { if } b_{i t}=\bar{b}\end{cases}
$$

and the random variables $M_{t+1, t}^{i}, i=1,2$ as

$$
\begin{aligned}
& M_{t+1, t}^{1}=\mathbf{1}\left(b_{1 t}>\bar{b}\right) m_{t+1, t}^{1}+\left[1-\mathbf{1}\left(b_{1 t}>\bar{b}\right)\right] m_{t+1, t}^{2} \\
& M_{t+1, t}^{2}=\mathbf{1}\left(b_{2 t}>\bar{b}\right) m_{t+1, t}^{2}+\left[1-\mathbf{1}\left(b_{2 t}>\bar{b}\right)\right] m_{t+1, t}^{1} .
\end{aligned}
$$

Then the random variables, $M_{t+1, t}^{i}$ are valid pricing kernels.

We solve this model computationally using the algorithm outlined in Telmer (1993). The vector of state variables, $\Omega_{t} \equiv\left[b_{1, t-1} Z_{1 t} I_{t}\right]$, is sufficient to characterize 
the state of the system at time $t$. An equilibrium is thus characterized by stationary pricing functionals, $B\left(\Omega_{t}\right)$ and $P\left(\Omega_{t}\right)$, and a trading rule, $b\left(\Omega_{t}\right)$. All other quantities in the model, state contingent consumption for instance, can be written in terms of the state vector and the equilibrium policy functionals.

In the numerical examples, parameters are set at relatively standard values. The preference parameters are $\delta=0.05$ and $\alpha=2$. The aggregate income growth process is chosen to match moments with annual U.S. aggregate consumption growth. It has has a mean of 1.018, a standard deviation of 0.036 , and an autocorrelation of -0.14 . The idiosyncratic endowment shock process, $Z_{1 t}$, has an unconditional mean of 0.5 , i.e., an equal share on average. The conditional variance is set to a constant value of 0.13 as in Heaton and Lucas (1992). The persistence of this process varies across examples as outlined in Table 1. (See the Appendix for further details about the specification of these processes.)

We now report population moments for four theoretical economies. The first economy is simply the Mehra and Prescott (1985) model, to which this model collapses should complete markets exist. The population moments for the complete markets model serve as a benchmark in terms of which deviations from first-best risk sharing represented by the other three economies can be evaluated. The other three economies differ in the persistence in the idiosyncratic component of labor income. In the second economy, the shocks, $Z_{1 t}$ are i.i.d, whereas in the third and fourth economies the coefficient of first order autocorrelation is 0.5 and 0.95 , respectively. In all three incomplete markets economies the borrowing constraint, $\bar{b}$, is set so that an individual cannot borrow more than one half of their average annual income. One reason for choosing this relatively restrictive specification is to avoid an equilibrium with close to perfect risk sharing. Recall that the results of Lucas (1994) and Telmer (1993) indicate that some combination of restrictive borrowing constraints and persistent idiosyncratic income shocks are necessary (in this environment) to generate interesting deviations from first-best risk sharing.

The noteworthy features of the theoretical economies we study are summarized in Table 1. Several asset-pricing puzzles associated with the complete-markets model are evident in the first column. The variability of the pricing kernel is too small (Hansen and Jagannathan (1991)), the average risk-free interest rate is too large, and the average excess return on equity is too small (Mehra and Prescott (1985)), to account for observed asset-market data.

The remaining three columns demonstrate that the properties of equilibrium prices in the incomplete-markets economy can be substantially different from the complete-markets economy. For instance, in the economy with an i.i.d. specification for $Z_{1 t}$, the borrowing constraint is sufficiently restrictive such that the unconditional probability of it binding is roughly $18 \%$. In these states the agent on the short side of the market is unable to buffer adverse income shocks by running down asset stocks. The result is an increase in consumption variability and, therefore, an increase in 
the variability of the pricing kernel. In addition, since the agent on the long side of the market must be dissuaded from going even longer (since the market clearing condition dictates that they must lend only as much as the short agent is allowed to borrow), the equilibrium interest rate decreases. Both of these effects serve to increase the equilibrium excess return on equity. Should the constraint be made less restrictive (such that it binds with probability less than, say, 1\%), Telmer (1993) finds that these effects are mitigated as agents are able to effectively buffer adverse income shocks in almost all states by adjusting asset holdings.

As the degree of persistence in idiosyncratic income increases, the incidence of binding borrowing constraints does as well, both in terms of the number of times that an agent hits the constraint as well as the duration of time before an agent becomes unconstrained. The equilibrium trading rule is such that an agent will run down their bond holdings when faced with a sequence of bad shocks. Once constrained, an agent will remain so until a favorable income shock is realized, at which time they will begin to accumulate bonds. The net effect of persistence then, is that the economic effects of the borrowing constraint (higher consumption, higher pricing kernel variability, lower interest rates, and a higher excess return on equity) are amplified. Note that these findings are consistent with the Constantinides-Duffie model in that persistence in idiosyncratic income tends to discourage risk sharing.

\section{Approximate Aggregation}

The true pricing kernel for these incomplete markets economies satisfies

$$
E\left[M_{t+1}^{1} R_{t+1} \mid \mathcal{F}_{t}\right]=1
$$

Our objective is to ask whether there exists a random variable $M_{t}^{G} \in \mathcal{G}_{t}$ which, under ideal circumstances, satisfies

$$
E\left[M_{t+1}^{G} R_{t+1} \mid \mathcal{F}_{t}\right]=1
$$

We begin by asking whether approximate versions of the results for the autarkic economies in Section 3.1 hold. That is, we specify functional forms for a pricing kernel that apply exactly for several well known representative agent economies and ask if these random variables can be used to price assets in our incomplete markets economies.

Typically, an aggregate pricing kernel is specified only up to a finite number of unknown parameters, e.g., the rate of time preference, the coefficient of relative risk aversion, etc. Therefore, to investigate the pricing properties of these models, 
we must first choose suitable values for these parameters. We follow the standard econometric procedure of choosing these values to match certain moments of aggregate variables to their values implied under the (false) aggregate model. Consider the ex post Euler equation from a typical aggregate model:

$$
M_{t+1}^{G} R_{t+1}-1=\varepsilon_{t+1}+\eta_{t+1}
$$

where

$$
\varepsilon_{t+1} \equiv M_{t+1}^{1} R_{t+1}-E_{t} M_{t+1}^{1} R_{t+1}
$$

is the forecast error and

$$
\eta_{t+1} \equiv\left(M_{t+1}^{G}-M_{t+1}^{1}\right) R_{t+1}
$$

is the approximation error. There is also potential for a third type of error affecting this Euler equation. An exact aggregate pricing kernel, $M_{t+1}^{G}$, could exist, but could be misspecified in econometric applications. Since this subtle distinction is somewhat tangential to the focus of this paper, we will subsume this type of error in the general approximation error.

The restrictions we use to identify parameters assume either $\eta_{t+1}=0$ or $E\left[\eta_{t+1} \mid \mathcal{G}_{t}\right]=$ 0 . That is, approximation errors are simply ignored and the parameter estimates are obtained under the false hypothesis that the model aggregates and is correctly specified. This procedure is adopted in an attempt to reflect what is typically done in empirical applications. Moreover, if the aggregate model does in fact provide a close approximation to the true model, these errors should be small and uncorrelated with period- $t$ aggregate information.

For each of the candidate models described below, we use two asset returns and three instruments for estimation. We focus on the return on the aggregate endowment, i.e. the equity return, and the return on the one-period pure-discount bond. We use as instruments a constant, the lagged equity return, and the lagged bond return. We, therefore, impose the six moment restrictions

$$
\begin{aligned}
& E\left[z_{t}\left(M_{t+1}^{G} R_{t+1}^{m}-1\right)\right]=0 \\
& E\left[z_{t}\left(M_{t+1}^{G} R_{t+1}^{b}-1\right)\right]=0,
\end{aligned}
$$

where $z_{t}=\left[\begin{array}{lll}1 & R_{t}^{m} & R_{t}^{b}\end{array}\right]$. Unlike the typical empirical researcher, we eliminate the role of sampling error in this estimation step by calculating these moments exactly 
given our knowledge of the probability structure of the theoretical economy. (In practice, we use the mean from a simulated series with 10,000 observations rather than undertaking the necessary integration.) Since in every case we consider below, we have fewer than six parameters, we choose the values that minimize the sum of squares of these six moments.

This procedure is certainly open to modification. For example, we could choose different instruments that would result in a different set of moment restrictions. When the approximation errors are significant, the choice of instruments would result in different values for the parameters of the aggregate model. The restrictions that we impose we feel reflect what has become "standard procedure" in the empirical asset-pricing literature. Our approach is nonstandard in its use of exact population moments rather than sample moments.

\subsection{Time Separable Expected Utility}

A natural starting point is additively time-separable, constant relative risk aversion, expected utility. As detailed in Hansen and Singleton (1982) the asset pricing kernel is given by

$$
M_{t+1}^{G}=\left(\frac{1}{1+\delta}\right)\left[\frac{C_{1, t+1}+C_{2, t+1}}{C_{1, t}+C_{2, t}}\right]^{-\alpha}=\left(\frac{1}{1+\delta}\right)\left[\frac{I_{t+1}}{I_{t}}\right]^{-\alpha}
$$

Note that this is the aggregate model that would result if the borrowing constraints were not binding or if markets were complete. Since it depends only on the growth rate of aggregate income, it does not vary with either idiosyncratic income or with the distribution of wealth.

The parameter values for this model, for each degree of persistence in the idiosyncratic shock process, are given in Table 2. Note that in each case the the risk aversion parameter is relatively small in absolute value. Note also that is is not equal to the individual agents' value of 2 .

In Figures 4 through 6 we examine the state-by-state pricing errors associated with the candidate pricing kernel, $M_{t+1}^{G}$. Figure 4 reports results for an economy with iid idiosyncratic shocks, Figure 5 for an economy with positively autocorrelated shocks $\left(\rho_{z}=0.5\right)$ and Figure 6 for an economy with extremely persistent shocks $\left(\rho_{z}=0.95\right)$. The top panel of each figure corresponds to the expected utility-based approximate pricing kernel, whereas the middle-panel corresponds to the pricing kernel discussed below. The bottom panel reports the stationary (cumulative) distribution associated with the states shown on the horizontal axis.

More precisely, what Figures 4 through 6 graph are the state-contingent interest rate functions implied by the actual and approximate pricing kernels. The solid line represents the actual interest rate function, 


$$
-\log \left[E\left(M_{t+1}^{1} \mid \mathcal{F}_{t}\right)\right]
$$

whereas the dashed line represents the interest rate function implied by the approximate pricing kernel,

$$
-\log \left[E\left(M_{t+1}^{G} \mid \mathcal{F}_{t}\right)\right]
$$

Computation of these conditional moments is straightforward given the discrete probabilistic structure of our economy. The difference between the solid and dashed lines are the state contingent pricing errors, expressed as interest rate errors.

For the expected utility specification it is clear that, to the extent that asset prices vary across the distribution of wealth, $M_{t+1}^{G}$ will misprice the bond. Since $M_{t+1}^{G}$ depends only on aggregate income growth, its conditional mean will be constant across any value for $b_{t-1}$. This is evident in each of the top panels in Figures 4 through 6 : the dashed line is constant across regions of the state space in which the aggregate shock is held constant and the distribution of wealth is varied. Since the actual interest rate does indeed vary with changes in the wealth distribution, we see that the candidate pricing kernel does not, in general, get the price right (or equivalently, get the interest rate right).

To understand how the vertical position of the approximate interest rate function is determined, recall that our method of parameterizing $M_{t+1}^{G}$ does so in such a way that some function (i.e., several moments) of each state-contingent pricing error is minimized. The weights given to each error will depend on both the unconditional probability of that state being realized as well as the model's dynamic properties which are governed by the conditional distribution. Our choice of moments, outlined in the previous section, dictates which of these dynamic properties get emphasized. An informal characterization of the expected utility results in Figures 4 through 6 is simply that our method-of-moments approach to parameterizing $M_{t+1}^{G}$ chooses parameter values so as to minimize the average pricing error. Note that it is crucial to incorporate the stationary distribution. For instance, in Figure 6 almost all the probability mass is concentrated on the corner: $b_{t-1}=-0.25$. Consequently our procedure selects parameter values that give the pricing error for this state a relatively large weight.

In Table 3 we evaluate the approximation error using a metric which summarizes information in Figures 4 to 6 : the unconditional mean and standard deviation of the riskless interest rate implied by the approximate pricing kernel. The top panel reports moments for the "true" (theoretical) interest rate, while the middle panel reports moments implied by the expected utility-based pricing kernel. These moments are consistent with our intuitive characterization of the results in Figures 4 
through 6 . The mean interest rate obtained using the approximate pricing kernel is quite close to the actual mean. In spite of the fact that the approximate kernel makes substantial state-contingent pricing errors, on average these errors are close to zero. Higher moments are a different story however. Table 3 shows that the standard deviation of the interest rate implied by $M_{t+1}^{G}$ is substantially lower than that implied by the true theoretical pricing kernel. In the next section we will see that by incorporating a return into the approximate pricing kernel we go a long way towards rectifying this.

Before moving on, it is worthwhile to note that our numerical results are similar in spirit to the theoretical results of Constantinides and Duffie (1996). We find that an approximate pricing kernel with the same functional form as an individual agent's intertemporal marginal rate of substitution works (for the mean), but that the parameter values at which it works cannot be interpreted as those reflecting an actual agent's preferences. In fact, the numerical values we obtain (Table 2) are qualitatively consistent with estimates obtained in representative agent estimation exercises (e.g., Hansen and Singleton (1982)). In this precisely defined sense one can argue that our incomplete markets economy can account for these previous, widely cited, empirical findings. Put differently, if the true model were one which exhibits uninsurable idiosyncratic risk of the form modeled here, then by estimating a misspecified representative agent model one would naturally be led to conclude that the agent had negative time preference and extreme risk aversion.

To summarize so far, we find that along a very simple dimension - the unconditional mean - approximate aggregation seems to hold quite precisely. However along most other dimensions, state-by state pricing errors and higher moments of interest rates for instance, the expected utility-based pricing kernel provides a poor approximation of the actual kernel. This is particularly true for states which imply a corner solution and for economies with persistent income shocks. The reason is simple - the aggregate consumption-based specification remains constant across different realizations for the wealth distribution. Not surprisingly, it appears that a viable pricing kernel that depends only on aggregate information will have to include some sort of proxy for variations in the distribution of wealth. This motivates our next candidate pricing kernel which uses the most natural proxy: the return on the market portfolio.

\subsection{Kreps-Porteus Recursive Utility}

A second preference-based candidate for $M_{t}^{G}$ is the Kreps-Porteus model studied by Epstein and Zin (1991b). In this model, the pricing kernel is given by

$$
M_{t+1}^{G}=\left[\left(\frac{1}{1+\delta}\right)\left(\frac{I_{t+1}}{I_{t}}\right)^{-1 / \sigma}\right]^{\frac{(1-\alpha) \sigma}{\sigma-1}}\left[\frac{1}{R_{t+1}^{m}}\right]^{1-\frac{(1-\alpha) \sigma}{\sigma-1}}
$$


where $\sigma$ is interpreted as the elasticity of intertemporal substitution and $\alpha$ as the coefficient of relative risk aversion for the representative agent.

This model is motivated by the desire to separate relative risk aversion from intertemporal substitution. Just as important for our purposes, however, is the fact that $M_{t}^{G}$ now takes the form of a geometric average of an aggregate consumptionbased pricing kernel and a market-portfolio-based pricing kernel. Insofar as the market return provides a proxy for individual-specific information, one might expect this formulation for $M_{t}^{G}$ to provide a better approximation of the actual pricing kernel, $M_{t}^{1}$, than did our previous candidate. Accordingly, one might expect the weight on the CAPM term to be relatively large.

\subsection{Linear Factor Model}

Our final approximate pricing kernel is based on a slightly more nonparametric approach to characterizing $M_{t}^{G}$. We know that the true pricing kernel lies in the relatively high dimensional space, $\mathcal{F}_{t}$. Furthermore, as Hansen and Richard (1987) have shown, the linear projection of $M_{t}^{1}$ onto some lower dimensional subspace, say the linear span of a vector of asset returns, will also constitute a valid pricing kernel for all assets with returns which lie in this subspace. That is, given some vector of returns, $R_{t+1}^{*}$, the projection, say $M_{t+1}^{*}$, satisfies,

$$
E\left(M_{t+1}^{*} R_{t+1}^{*}\right)=\mathbf{1}
$$

That we can construct a pricing kernel based on aggregate information (i.e., returns) is therefore a tautology. That we can do so in a parsimonious manner is, however, not tautological. In spite of the fact that, by construction, the $M_{t+1}^{*}$ lies in a lower dimensional space than the actual pricing kernel, it is important to realize that it is defined in terms of a conditional inner product. Its functional form may therefore be quite complex (i.e., time varying). This, in addition to the fact that we may want to price assets outside the linear span of $R_{t+1}^{*}$, makes our question non-trivial.

In this section we ask if a suitably parameterized function of asset returns provides a useful approximate pricing kernel for our economy. To maintain our goal of parsimony, we will restrict the functional form to be linear with constant coefficients:

$$
M_{t+1}^{G}=\phi \cdot R_{t+1}^{*}
$$

where $\phi$ is a vector of parameters. We are interested in the extent to which the following equations are satisfied

$$
E\left[\left(R_{t+1}^{*} \phi\right) R_{t+1} \mid \mathcal{F}_{t}\right]=1
$$


We choose parameters for the linear model to satisfy the moment restrictions discussed in the previous section. We use as factors, a constant and the stock return (so that $R_{t+1}^{*}=R_{t+1}$ ). These values are given in Table 2 .

Our results for the linear factor model, both in terms of state-by-state pricing errors as well as unconditional moments, are very similar to those of the KrepsPorteus specification. Consequently we do not report the Kreps-Porteus results. To understand why the similarity arises, consider the two important dimensions along which the factor model differs from the Kreps-Porteus model. First, the functional form is not necessarily the same: the market return enters as a term in a geometric average in latter, and as an arithmetic average in the former. This turns out to be quantitatively unimportant. Second, the two specifications differ in terms of which factors are used to proxy for the wealth distribution. Our results suggest that the bond return does not add incremental information, above and beyond the market return.

The middle panels of Figures 4 through 6 report state-contingent pricing errors for this approximate kernel in the same manner as the last section. The striking feature of these figures is the extent to which the market return does indeed provide an accurate proxy for the wealth distribution. In particular, the approximate kernel does quite well in all three cases at identifying the region of the state space where the wealth distribution matters most: the point at which the borrowing constraint becomes binding. Note also that, once again, knowledge of the unconditional distribution is crucial for interpreting the results. In Figure 6 for instance we see relatively large pricing errors occurring for states where agent 1 has positive assets. However these errors are almost insignificant once one considers the probability with which they occur. Table 3 confirms this to a certain extent where we see that the approximate pricing kernels of both the Kreps-Porteus and the linear factor models imply an interest rate with the first two moments quite close to those of the actual interest rate.

\section{Conclusion}

Much of the recent progress in intertemporal asset pricing theory has seen the introduction of various frictions into the classical Arrow-Debreu model of securities markets. These models have the potential to address a wide range of theoretical and empirical issues that their predecessors could not. However models with frictions, such as the incomplete markets economies we study here, have increasingly departed from what we feel is a tenet of valuation theory: parsimony. The main question we ask here is whether a model that admits the existence of certain frictions (frictions that are plausible and that help move the theory closer to the data), is at odds with the goal of parsimony. We find that it is not. We have shown, albeit in a very specific environment, that structural asset pricing models with a strong theoretical 
base need not be at odds with reduced-form specifications which, in practice, tend to "work" better. In particular, pricing kernels that are simple functions of equilibrium prices (or returns), provide good proxies for "actual" pricing kernels that are typically higher dimensional functions of disaggregate information. The reason for this is simple. In our model, equilibrium returns vary across the distribution the wealth. Our results simply suggest that a suitably parameterized function of these returns is able to reveal much of the relevant information regarding the underlying variation in the wealth distribution.

We find these approximate aggregation results encouraging for a number of reasons. On the positive side, they provide for a formal theoretical interpretation of why pricing models based on prices tend to be a practitioner's first choice. We feel that the theory behind our interpretation is both richer and more plausible than textbook theoretical interpretations, such as the static, frictionless, mean-variance framework. On the normative side we are encouraged by the possibility that dynamic optimization models may provide guidance in terms of constructing reduced-form factor structures which, for many applications, are certainly more useful. Finally, our results suggest that a more plausible interpretation of agent's information processing capabilities than is typically put forth in the context of incomplete markets economies. Taken literally, the model assumes that agents make decisions based not only on their own portfolio composition, but on every other agent's as well. Our results suggest that, in this competitive environment, a much more plausible information set may be sufficient: the contemporaneous return on the market portfolio. 


\section{References}

Aiyagari, S. R. and M. Gertler, (1991), Asset returns with transactions costs and uninsured individual risk, Journal of Monetary Economics 27, 311-331.

Alvarez, F. and U. Jermann, (1997), Asset pricing when risk sharing is limited by default, Unpublished working paper, University of Chicago.

Bossaerts, P. and R. C. Green, (1989), A general equilibrium model of changing risk premia: Theory and tests, Review of Financial Studies 2, 467-494.

Breeden, D. T., (1979), An intertemporal asset pricing model with stochastic consumption and investment opportunities, Journal of Financial Economics 7, $265-296$.

Cecchetti, S. G., P. Lam, and N. C. Mark, (1993), The equity premium and the risk free rate: matching the moments,. Journal of Monetary Economics 31, 21-45.

Chen, N., R. Roll, and S. Ross, (1986), Economic forces and the stock market, Journal of Business 59, 383-403.

Constantinides, G. M., (1982), Intertemporal asset pricing with heterogeneous consumers and without demand aggregation, Journal of Business 55, 253-267.

Constantinides, G. M. and D. Duffie, (1996), Asset pricing with heterogeneous consumers, Journal of Political Economy 104, 219-240.

den Haan, W., (1994), Heterogeneity, aggregate uncertainty and the short term interest rate: a case study of two solution techniques, Working paper, University of California at San Diego.

Duffie, D., (1996), Dynamic Asset Pricing Theory, Princeton University Press, Princeton, NJ.

Epstein, L. G. and S. E. Zin, (1991a), The independence axiom and asset returns, NBER working paper No. T0109.

Epstein, L. G. and S. E. Zin, (1991b), Risk aversion, and the temporal behavior of consumption and asset returns: An empirical analysis, Journal of Political Economy 99, 263-286.

Fama, E. F. and K. R. French, (1996), Multifactor explanations of asset pricing anomalies, Journal of Finance 51, 55-84.

Ferson, W. E. and C. R. Harvey, (1991), The variation of economic risk premiums, Journal of Political Economy 99, 385-415. 
Grossman, S. J. and R. J. Shiller, (1982), Consumption correlatedness and risk measurement in economies with non-traded assets and heterogeneous information, Journal of Financial Economics 10, 195-210.

Hansen, L. P. and R. Jagannathan, (1991), Implications of security market data for models of dynamic economies, Journal of Political Economy 99, 225-262.

Hansen, L. P. and S. F. Richard, (1987), The role of conditioning information in deducing testable restricions implied by dynamic asset pricing models, Econometrica 55, 587-613.

Hansen, L. P. and K. Singleton, (1982), Generalized instrumental variables estimation of nonlinear rational expectations models, Econometrica 50, 1269-1286.

Heaton, J. and D. J. Lucas, (1996), Evaluating the effects of incomplete markets on risk sharing and asset pricing, Journal of Political Economy 104, 443-487.

Jagannathan, R. and Z. Wang, (1996), The conditional capm and the cross-section of expected returns, Journal of Finance 51, 3-53.

Krusell, P. and A. A. Smith, (1997), Income and wealth heterogeneity, portfolio choice, and equilibrium asset returns, Macroeconomic Dynamics 1, 387-422.

Lehmann, B. N. and D. Modest, (1988), The empirical foundations of the arbitrage pricing theory, Journal of Financial Economics 21, 213-254.

Levine, D. K. and W. R. Zame, (2000), Does market incompleteness matter?, Unpublished manuscript, UCLA.

Lintner, J., (1965), The valuation of risky assets and the selection of risky investments in stock portfolios and capital budgets., Review of Economics and Statistics .

Lucas, D. J., (1994), Asset pricing with undiversifiable risk and short sales constraints: Deepening the equity premium puzzle, Journal of Monetary Economics $34,325-341$.

Lucas, R., (1978), Asset prices in an exchange economy, Econometrica 46, 1429 1445 .

Mankiw, N. G., (1986), The equity premium and the concentration of aggregate shocks, Journal of Financial Economics 17, 211-219.

Marcet, A. and K. J. Singleton, (1991), Equilibrium assets prices and savings of heterogeneous agents in the presence of portfolio constraints, forthcoming, Macroeconomic Dynamics. 
Mehra, R. and E. Prescott, (1985), The equity puzzle, Journal of Monetary Economics $15,145-61$.

Ross, S. A., (1976), The arbitrage theory of capital asset pricing, Journal of Economic Theory 13, 341-360.

Sharpe, W. F., (1964), Capital asset prices: A theory of market equilibrium under conditions of risk, Journal of Finance 19, 425-42.

Telmer, C. I., (1993), Asset pricing puzzles and incomplete markets, Journal of Finance 48, 1803-1832.

Zhang, H., (1997), Endogenous borrowing constraints with incomplete markets, Journal of Finance 52, 2187-2209. 


\section{Appendix}

Parameter Values and Stochastic Process Specifications

\section{Preferences and Budget Constraints}

$$
\begin{gathered}
U_{i}=E_{0}\left[\sum_{t=0}^{\infty}(1-\delta)^{-t} u\left(C_{i t}\right)\right], u(C)=\frac{C^{1-\alpha}}{1-\alpha}, \delta=0.05, \alpha=2 \\
C_{i t}=Y_{i t}+b_{i, t-1}-B_{t} b_{i t} \\
\Rightarrow C_{i t} / I_{t}=Z_{i t}+b_{i, t-1} /\left(I_{t-1} \lambda_{t}\right)-B_{t} / I_{t} b_{i t}
\end{gathered}
$$

where $Z_{i t}$ and $\lambda_{t}$ are defined below.

Aggregate Endowment:

$$
\begin{aligned}
I_{t} & =\lambda_{t} I_{t-1}, \lambda_{t} \in\left\{\lambda_{1} \lambda_{2}\right\} \\
\pi_{j k} & =P\left(\lambda_{t}=\lambda_{k} \mid \lambda_{t-1}=\lambda_{j}\right) \\
\pi & =P\left(\lambda_{t}=\lambda_{1}\right) \\
\lambda_{1} & =\mu_{a}+[\pi /(1-\pi)]^{1 / 2} \sigma_{a} \\
\lambda_{2} & =\mu_{a}-[(1-\pi) / \pi]^{1 / 2} \sigma_{a}
\end{aligned}
$$

\section{Idiosyncratic Shock:}

$$
\begin{aligned}
Y_{1 t} & =Z_{1 t} I_{t}, Z_{1 t} \in\left\{Z_{1} Z_{2}\right\} \\
Y_{2 t} & =\left(1-Z_{1 t}\right) I_{t} \\
\omega_{j k} & =P\left(Z_{1 t}=Z_{k} \mid Z_{1, t-1}=Z_{j}\right) \\
\omega & =P\left(Z_{1 t}=Z_{1}\right)
\end{aligned}
$$

\section{Parameter Values:}

- The transition matrix $\Pi \equiv \pi_{j k}$ is constrained to be symmetric (so that the unconditional probability, $\pi$, is equal to $1 / 2$ ) and is characterized by one parameter, $\pi_{11}$. This parameter is chosen to match the coefficient of first-order autocorrelation for aggregate U.S. consumption growth, $\rho=-0.14$, which gives $\pi_{11}=0.43 . \quad \mu_{a}$ and $\sigma_{a}$ are chosen to match the mean and standard deviation of consumption growth, respectively, which gives $\mu_{a}=1.018$ and $\sigma_{a}=0.036$.

- The parameters describing the idiosyncratic endowment shock process, $Z_{1 t}$, are chosen as follows. The unconditional mean is set to $1 / 2$. The coefficient of first-order autocorrelation is set according to the economy in question (see Table 1). The remaining parameter is chosen so that the conditional variance of the process is constant at 0.13. This value is taken from and Heaton and Lucas (1992) who estimate a first-order autoregression similar to that presented in the text, using data from the Panel Study on Income Dynamics (PSID). 
Table 1

Properties of Theoretical Economies

\begin{tabular}{|c|c|c|c|c|c|}
\hline & & $\begin{array}{r}\text { Complete } \\
\text { Markets } \\
\end{array}$ & $\rho_{z}=0$ & $\rho_{z}=0.5$ & $\rho_{z}=0.95$ \\
\hline \multirow{2}{*}{$M_{1}$} & mean & 0.920 & 0.949 & 0.983 & 1.133 \\
\hline & s.d. & 0.065 & 0.142 & 0.218 & 0.921 \\
\hline \multirow{2}{*}{$R^{b}$} & mean $(\%)$ & 8.3 & 5.3 & 1.9 & -12.8 \\
\hline & s.d. $(\%)$ & 0.9 & 4.9 & 5.3 & 1.6 \\
\hline \multirow{2}{*}{$R^{m}$} & mean $(\%)$ & 8.9 & 8.6 & 8.1 & 3.0 \\
\hline & s.d. $(\%)$ & 4.3 & 1.1 & 13.9 & 5.5 \\
\hline \multirow{2}{*}{$R^{m}-R^{b}$} & mean $(\%)$ & 0.6 & 3.3 & 6.2 & 15.8 \\
\hline & s.d. $(\%)$ & 4.3 & 9.4 & 12.1 & 5.1 \\
\hline
\end{tabular}

See the appendix for details on the specific parameter values and stochastic process specifications used to compile this table. The asset market structure in these economies consists of a riskless discount bond in zero net supply, and a non-traded, zero-net supply claim on the aggregate endowment process. One interpretation of the latter market structure is that a short-sales constraint applies to the zero-net supply equity claim. A borrowing constraint equal to $1 / 4$ of the aggregate endowment, $Y_{t}$, is imposed on the bond market. 
Table 2

Parameter Values

\begin{tabular}{|c|c|c|c|}
\hline Parameter & $i i d$ & $\rho_{z}=0.5$ & $\rho_{z}=0.95$ \\
\hline \multicolumn{4}{|c|}{ I. Expected Utility } \\
\hline$\delta$ & 0.1177 & -0.0008 & -0.1149 \\
\hline$\alpha$ & -2.9482 & 1.3330 & -0.3134 \\
\hline \multicolumn{4}{|c|}{ II. Linear Factor Model } \\
\hline Constant & 1.9013 & 2.1000 & 2.1326 \\
\hline$R^{m}$ & -0.8765 & -1.0328 & -0.9666 \\
\hline
\end{tabular}

Table 3

Interest Rate Moments: Exact and Approximate

\begin{tabular}{|c|c|c|c|c|c|}
\hline & & $\begin{array}{r}\text { Complete } \\
\text { Markets }\end{array}$ & $\rho_{z}=0$ & $\rho_{z}=0.5$ & $\rho_{z}=0.95$ \\
\hline \multirow{2}{*}{$R$} & mean $(\%)$ & 8.3 & 5.60 & 2.03 & -11.97 \\
\hline & s.d. $(\%)$ & 0.9 & 4.97 & 5.32 & 1.39 \\
\hline \multirow{2}{*}{$R^{E U}$} & mean $(\%)$ & & 5.69 & 2.13 & -11.97 \\
\hline & s.d. $(\%)$ & & 1.54 & 0.67 & 0.14 \\
\hline \multirow{2}{*}{$R^{L F}$} & mean $(\%)$ & & 5.62 & 2.30 & -11.96 \\
\hline & s.d. $(\%)$ & & 5.22 & 8.31 & 1.86 \\
\hline
\end{tabular}


Figure 1: Ex Post $\log (M R S): \mathrm{A}=1, \lambda=2$
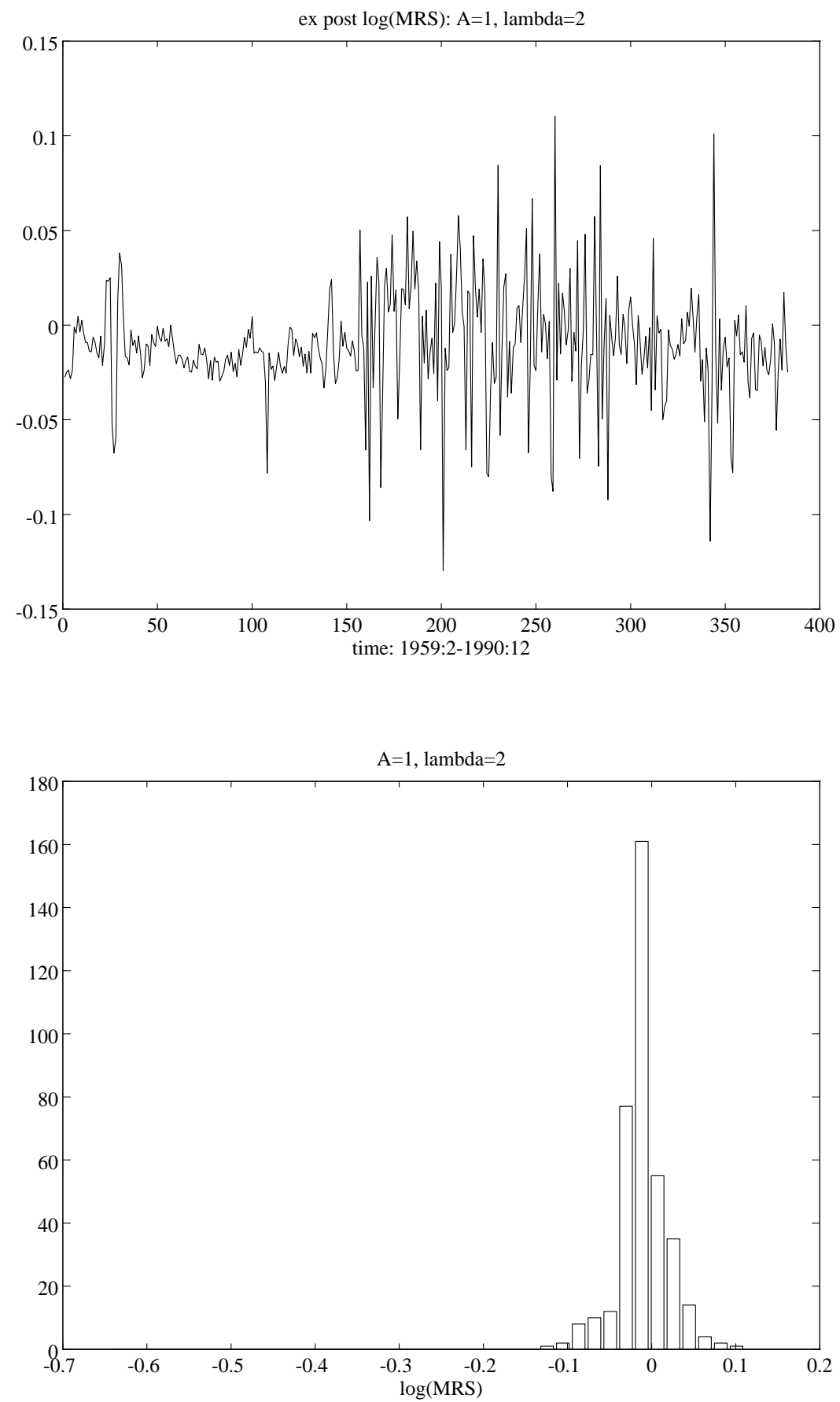
Figure 2: Ex Post $\log (M R S): \mathrm{A}=0.8, \lambda=2$
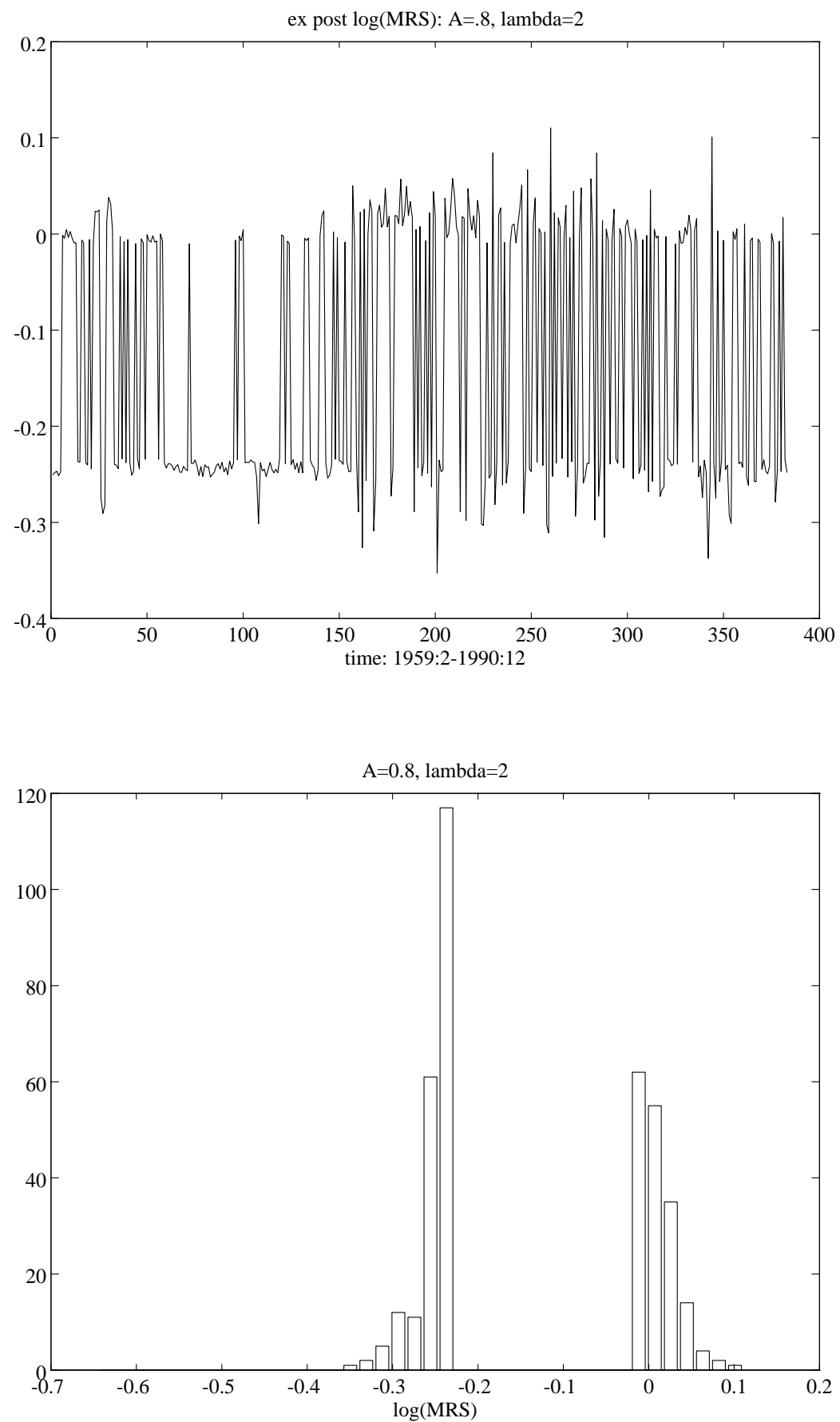
Figure 3: Ex Post $\log (M R S): \mathrm{A}=0.6, \lambda=2$
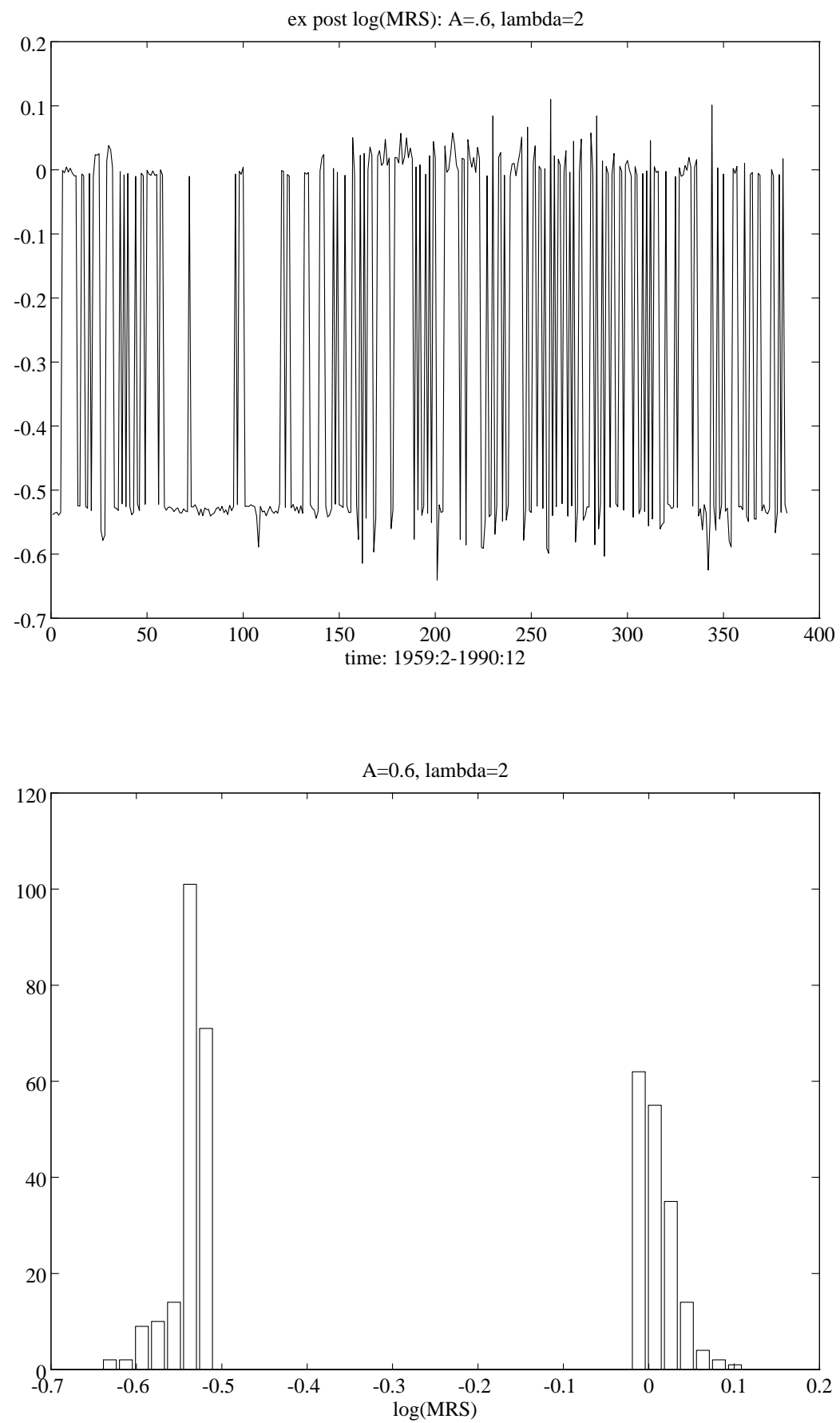
Figure 4: Actual and Approximate Interest Rate Functions (iid $(\rho=0)$ economies)
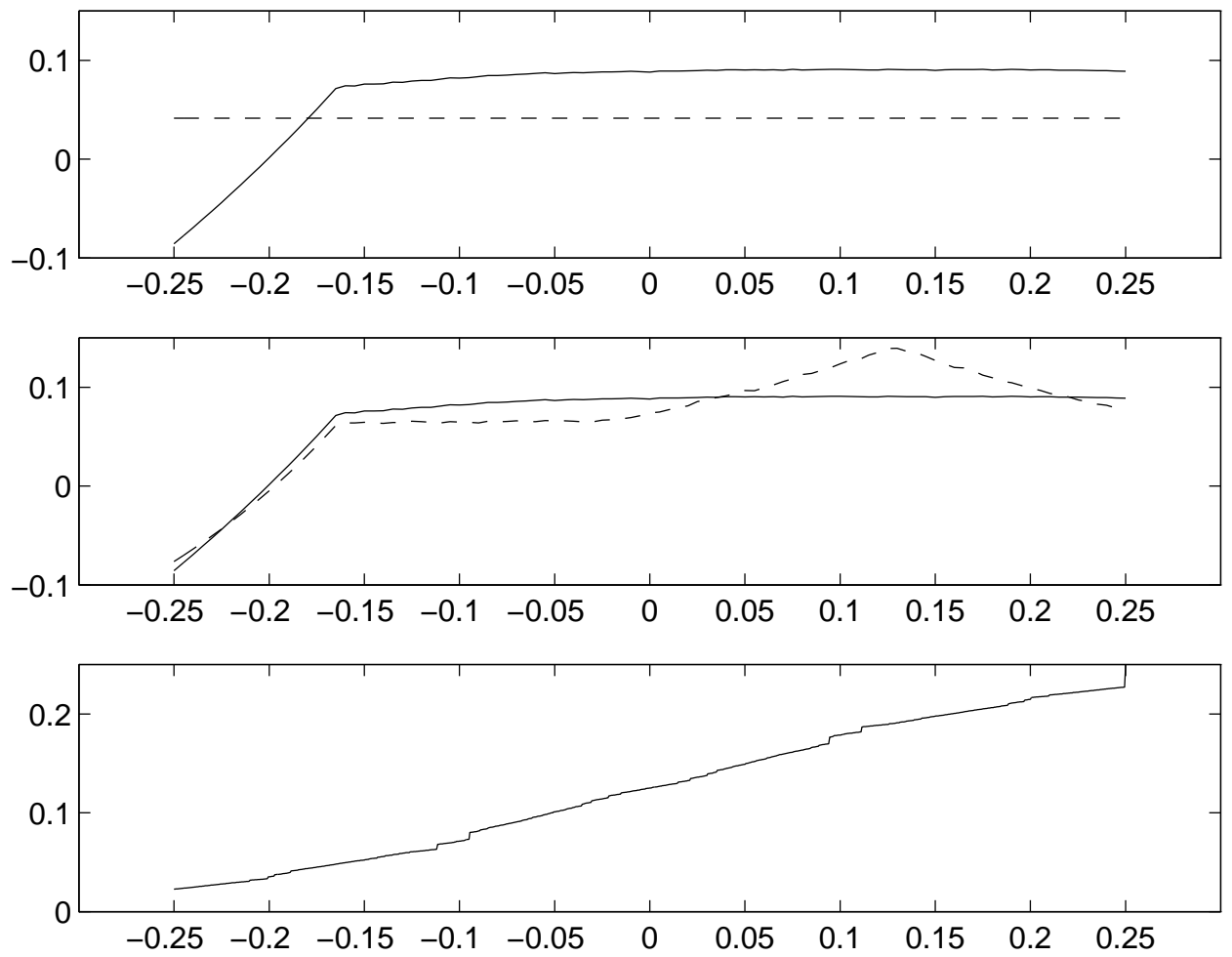

Notes: Each of the top two figures reports the state-by-state interest rate associated with the actual pricing kernel (solid line) and an approximate pricing kernel (dashed line), graphed against the distribution of wealth. As is discussed in the text, the distribution of wealth is represented by the beginning-of-period bond holdings of agent 1 (agent 2's bond holdings are equal to the negative of agent 1's). The top figure corresponds to the the expected utility pricing kernel (section 4.1) whereas the middle figure corresponds to the Linear-Factor pricing kernel (section 4.3). The bottom figure reports the stationary (cumulative) distribution associated with the states that are represented on the horizontal axis. We report results only for the state in which agent one receives the bad idiosyncratic shock and the aggregate endowment growth rate is low. Results for the other three states (bad shock - high growth, good shock - low growth and good shock - high growth) are very similar to those reported here, with the caveat that, should agent 1 receive the good idiosyncratic shock, the pricing functionals would be mirror images of those shown above. 
Figure 5: Actual and Approximate Interest Rate Functions (persistent $(\rho=0.5)$ economies)
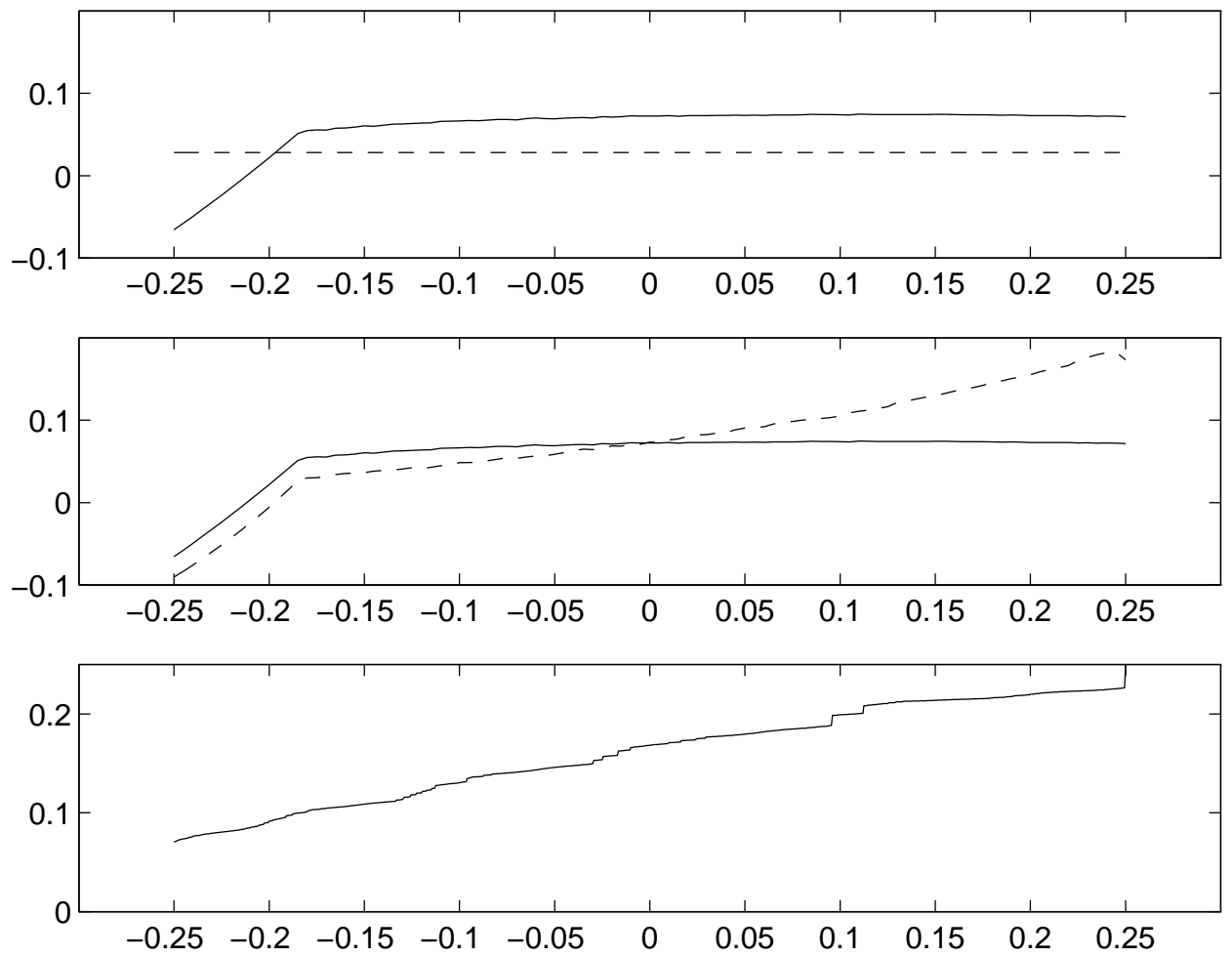

Notes: Each of the top two figures reports the state-by-state interest rate associated with the actual pricing kernel (solid line) and an approximate pricing kernel (dashed line), graphed against the distribution of wealth. As is discussed in the text, the distribution of wealth is represented by the beginning-of-period bond holdings of agent 1 (agent 2's bond holdings are equal to the negative of agent 1's). The top figure corresponds to the the expected utility pricing kernel (section 4.1) whereas the middle figure corresponds to the Linear-Factor pricing kernel (section 4.3). The bottom figure reports the stationary (cumulative) distribution associated with the states which are represented on the horizontal axis. We report results only for the state in which agent one receives the bad idiosyncratic shock and the aggregate endowment growth rate is low. Results for the other three states (bad shock - high growth, good shock - low growth and good shock - high growth) are very similar to those reported here, with the caveat that, should agent 1 receive the good idiosyncratic shock, the pricing functionals would be mirror images of those shown above. 
Figure 6: Actual and Approximate Interest Rate Functions (persistent $(\rho=0.95)$ economies)
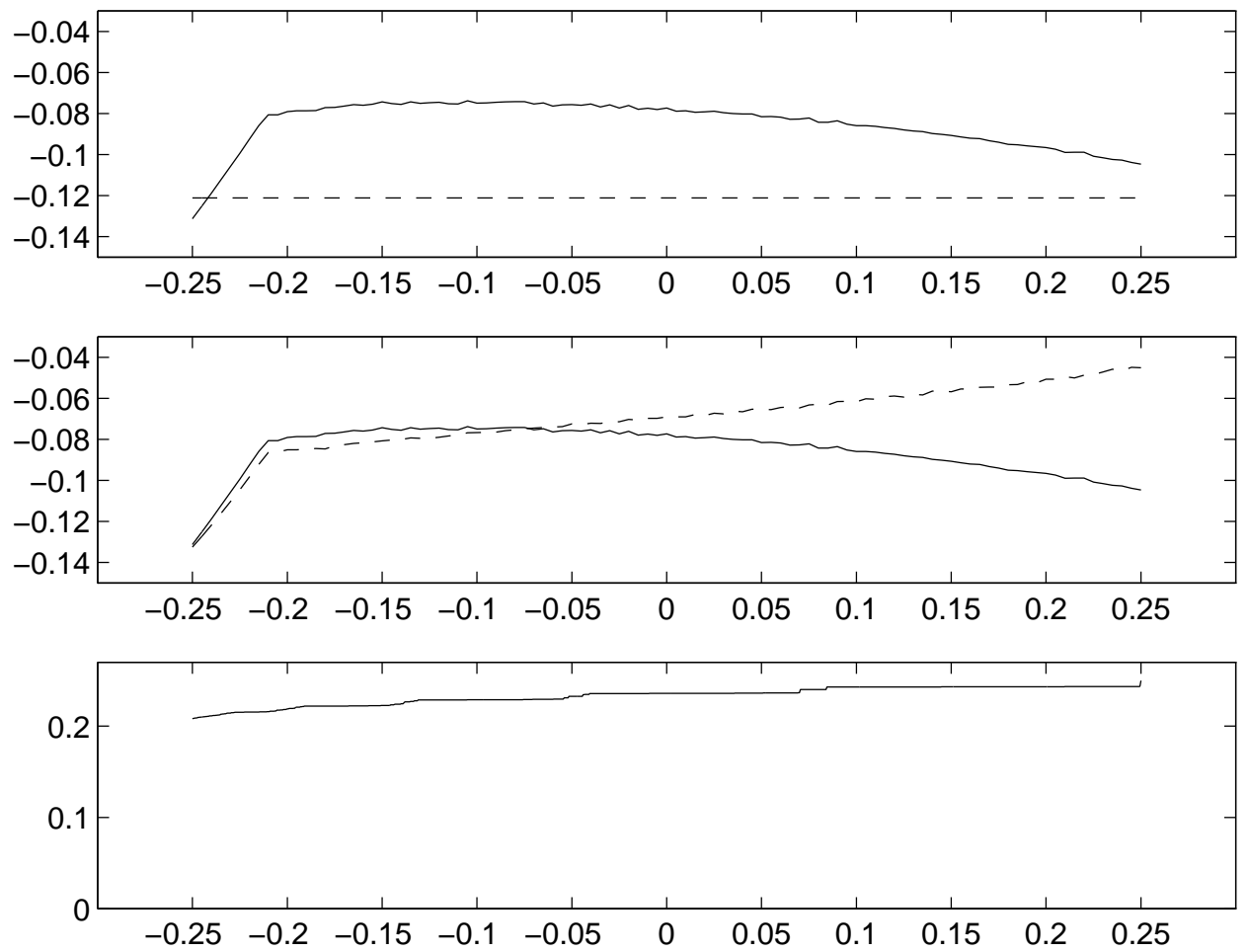

Notes: Each of the top two figures reports the state-by-state interest rate associated with the actual pricing kernel (solid line) and an approximate pricing kernel (dashed line), graphed against the distribution of wealth. As is discussed in the text, the distribution of wealth is represented by the beginning-of-period bond holdings of agent 1 (agent 2's bond holdings are equal to the negative of agent 1's). The top figure corresponds to the the expected utility pricing kernel (section 4.1) whereas the middle figure corresponds to the Linear-Factor pricing kernel (section 4.3). The bottom figure reports the stationary (cumulative) distribution associated with the states which are represented on the horizontal axis. We report results only for the state in which agent one receives the bad idiosyncratic shock and the aggregate endowment growth rate is low. Results for the other three states (bad shock - high growth, good shock - low growth and good shock - high growth) are very similar to those reported here, with the caveat that, should agent 1 receive the good idiosyncratic shock, the pricing functionals would be mirror images of those shown above. 